CLINICAL STUDY

\title{
Gene expression profiles in aldosterone-producing adenomas and adjacent adrenal glands
}

\author{
Tao Wang ${ }^{1,2}$, Fumitoshi Satoh ${ }^{3}$, Ryo Morimoto ${ }^{3}$, Yasuhiro Nakamura ${ }^{4}$, Hironobu Sasano ${ }^{4}$, Richard J Auchus ${ }^{5}$, \\ Michael A Edwards ${ }^{6}$ and William E Rainey ${ }^{1}$ \\ ${ }^{1}$ Department of Physiology, Medical College of Georgia, 1120 15th Street, Augusta, Georgia 30912, USA, ${ }^{2}$ Department of Cardiology, Renmin Hospital of \\ Wuhan University, Wuhan, 430060 People's Republic of China, ${ }^{3}$ Division of Nephrology, Endocrinology, and Vascular Medicine, Department of Medicine \\ and ${ }^{4}$ Department of Pathology, Tohoku University Graduate School of Medicine, Sendai 980-8574, Japan, ${ }^{5}$ Division of Endocrinology and Metabolism, \\ Department of Internal Medicine, UT Southwestern Medical Center, Dallas, Texas 75390-8857, USA and ${ }^{6}$ Department of Surgery, Medical College of \\ Georgia, Augusta, Georgia 30912, USA \\ (Correspondence should be addressed to W E Rainey; Email: wrainey@mcg.edu)
}

\begin{abstract}
Background: Primary aldosteronism (PA) is the most common form of endocrine hypertension affecting $\sim 8-10 \%$ of hypertensive subjects. Aldosterone production in PA occurs under low-renin conditions, and the mechanisms that maintain the production of aldosterone in PA remain unknown.

Objective: This study was designed to compare the transcript profiles between aldosterone-producing adenoma (APA) and their adjacent adrenal gland (AAG) from the same adrenal.

Methods: Total RNA was extracted from ten APA and ten AAG; and subsequently analyzed by microarray and real-time quantitative RT-PCR (qPCR). The microarray data were paired for each APA-AAG, and analyzed by GeneSpring GX 11 with paired $t$-test and fold change calculations for each transcript. Changes identified by microarray analysis were confirmed by qPCR.

Results: Microarray analysis indicated that 14 genes had significantly up-regulated expression in APA compared to AAG. Among the elevated genes were aldosterone synthase (CYP11B2) as well as novel transcription factors, calmodulin-binding proteins, and other genes that have not been previously studied in APA. Selective analysis of 11 steroidogenic enzymes using microarray demonstrated that only CYP11B2 showed a significantly higher transcript level in APA compared to AAG $(P<0.001)$. In contrast, AKR1C3 (17 $\beta$-hydroxysteroid dehydrogenase type 5), CYP17 (17 $\alpha$-hydroxylase/17,20 lyase), and CYB5 (cytochrome b5) showed significantly lower transcript level in APA $(P<0.05)$.

Conclusion: The transcriptome analysis of APA compared with AAG showed several novel genes that are associated with APA phenotype. This gene list provides new candidates for the elucidation of the molecular mechanisms leading to PA.
\end{abstract}

European Journal of Endocrinology 164 613-619

\section{Introduction}

Primary aldosteronism (PA) is the most common endocrine-related cause of hypertension and affects $\sim 8-10 \%$ of hypertensive patients $(1,2)$. Moreover, with an inappropriate production of aldosterone, PA is associated with more severe cardiovascular, renal, and other complications compared with primary hypertension $(3,4)$. In $\sim 30-60 \%$ of PA patients, the cause is unilateral aldosterone-producing adenoma (APA) $(1,5-7)$.

Several studies have demonstrated that APA continues to express high levels of aldosterone synthase (CYP11B2), which maintains the capacity for aldosterone production (8-12). Expression of this enzyme is mainly regulated by plasma potassium concentration and renin-angiotensin II (Ang II) system (13-15).
Aldosterone production in APA, however, occurs under low renin conditions $(16,17)$, and the mechanisms that maintain high CYP11B2 expression and hypersecretion of aldosterone in APA remain unknown.

Previous studies have examined the gene expression pattern in APA compared with normal adrenal tissues (8, 10-12, 18); however, direct comparison between APA and adjacent adrenal gland (AAG) tissue from the same patient has not been performed. Herein, we compared the gene expression profiles between APA and AAG tissues from ten surgical specimens using high-density oligonucleotide microarray and real-time quantitative RT-PCR (qPCR). Our results define that some genes were expressed at significantly higher levels in APA than in AAG, which have not been identified as markers for APA in previous studies and might contribute to the pathophysiology of APA. 


\section{Materials and methods}

\section{Subjects and tissues}

Human adrenal glands, which contained APA tissue, were obtained as part of standard pathological evaluation in collaboration with Tohoku University Hospital (Sendai, Japan) and University of Texas Southwestern Medical Center (Dallas, TX, USA). Tumor and AAG tissues were macroscopically dissected and were then snap frozen and stored at $-80{ }^{\circ} \mathrm{C}$. All samples were used under University Ethics Committee approval, and written informed consent was obtained from each patient. Thirteen adrenal glands were collected from patient with APA, two APA samples, which showed less than twofold changes of CYP11B2 compared with the AAG tissue, were excluded from our study, and one showed low quality of RNA was also excluded. Herein, we used ten APA-AAG pairs for microarray analysis.

\section{RNA isolation and cDNA generation}

Total RNA was isolated from frozen tissue using RNeasy Mini Kit (Qiagen) according to the manufacturer's instruction. The purity and quantity were assessed by a ND-1000 NanoDrop spectrophotometer (NanoDrop Technologies, Wilmington, DE, USA).

For cDNA generation, $2 \mu \mathrm{g}$ total RNA was reverse transcribed using the High Capacity cDNA Archive Kit (Applied Biosystems, Foster City, CA, USA) following the manufacturer recommendations and incubated at $25^{\circ} \mathrm{C}$ for $10 \mathrm{~min}, 37^{\circ} \mathrm{C}$ for $2 \mathrm{~h}$, and $85^{\circ} \mathrm{C}$ for $5 \mathrm{~s}$. The synthesized cDNA was subjected to 1:10 dilution for qPCR.

\section{Microarray analysis}

Total RNA isolated from APA and AAG tissues was treated with a first- and second-strand RT step, followed by a single in vitro transcription amplification that incorporated biotin-labeled nucleotides. Then, the labeled RNA was hybridized to a bead chip containing more than 48000 probes representing over 25000 human genes (Illumina, San Diego, CA, USA).
The arrays were scanned at high resolution on the iScan system (Illumina). Results were analyzed using GeneSpring GX (version 11) software (Silicon Genetics, Redwood City, CA, USA) to identify transcriptome differences between APA and AAG.

\section{Real-time quantitative RT-PCR}

Primers and probes, for selected genes, were designed based on published sequences, and gene amplification was performed using Taqman Gene Expression Assays (Applied Biosystems). The gene symbols and AB assay numbers are listed in Table 1. The primer and probe set for human CYP11B2 and CYP17 were designed using Primer Express 3.0 (Applied Biosystems) and purchased from IDT (Integrated DNA Technologies, Inc., Coralville, IA, USA) as described previously (19).

qPCR was performed using an ABI 7500 Fast RealTime PCR System (Applied Biosystems), with $5 \mu \mathrm{l}$ cDNA, $10 \mu \mathrm{l}$ TaqMan Fast Universal PCR Master Mix (2X; Applied Biosystems), $900 \mathrm{nM}$ of each primer, and $400 \mathrm{nM}$ probe in a total volume of $20 \mu \mathrm{l}$ per well according to the manufacturer's instruction. Negative controls contained water instead of cDNA. Quantitative normalization of cDNA in each tissue-derived sample was performed using expression of $18 \mathrm{~S}$ rRNA as an internal control. The generated $C_{t}$ value of each gene was normalized by its respective $C_{\mathrm{t}}$ value of $18 \mathrm{~S}$ rRNA $\left(\Delta C_{\mathrm{t}}\right)$. Each APA gene was then further normalized to the $\Delta C_{\mathrm{t}}$ value of its corresponding AAG $\left(\Delta \Delta C_{\mathrm{t}}\right)$. The final fold expression changes were calculated using the equation $2^{-\Delta \Delta C_{\mathrm{T}}}$.

\section{Statistical analysis}

The fold change of qPCR data between APA and AAG pairs was converted to logarithms, and then analyzed using paired $t$-test with the SigmaStat 3.0 software package (Chicago, IL, USA). The microarray data were analyzed using paired $t$-test with Benjamini and Hochberg False discovery rate (FDR) correction using GeneSpring GX11 software. $P$ value $<0.05$ was considered to be significant.

Table 1 Comparison of results from qPCR and microarray for APA-AAG pairs. The $\log _{2}$ fold changes were calculated for each APA-AAG pair and presented as mean \pm S.E.M.

\begin{tabular}{|c|c|c|c|c|c|}
\hline \multirow[b]{2}{*}{ Gene symbols } & \multirow[b]{2}{*}{ AB assay no. } & \multicolumn{2}{|c|}{ qPCR ( $\log _{2}$ fold change) } & \multicolumn{2}{|c|}{ Microarray ( $\log _{2}$ fold change) } \\
\hline & & Mean \pm s.E.M. & $P$ & Mean \pm S.E.M. & $P$ \\
\hline CYP11B2 & & $6.01 \pm 0.88$ & $<0.001$ & $3.28 \pm 0.41$ & $<0.001$ \\
\hline PCP4 & Hs01113638 m1 & $3.38 \pm 0.69$ & $<0.001$ & $2.80 \pm 0.67$ & 0.004 \\
\hline VPREB3 & $\mathrm{Hs} 00353682$ m1 & $3.30 \pm 0.40$ & $<0.001$ & $2.39 \pm 0.32$ & $<0.001$ \\
\hline$P R R X 1$ & Hs00246561_m1 & $1.69 \pm 0.25$ & $<0.001$ & $1.39 \pm 0.22$ & 0.001 \\
\hline$A L D H 1 A 2$ & Hs00180254_m1 & $3.09 \pm 0.60$ & $<0.001$ & $1.45 \pm 0.45$ & 0.010 \\
\hline CYP17A1 & & $-0.97 \pm 0.41$ & 0.042 & $-0.73 \pm 0.23$ & 0.023 \\
\hline CYB5 & Hs00157217_m1 & $-1.77 \pm 0.53$ & 0.009 & $-1.76 \pm 0.31$ & 0.001 \\
\hline AKR1C3 & Hs00366261_m1 & $-1.32 \pm 0.30$ & 0.002 & $-0.69 \pm 0.16$ & 0.004 \\
\hline
\end{tabular}

$P$ value was determined by paired $t$-test for each transcript. 


\section{Results}

\section{Patient information}

Before the removal of adrenal glands, all APA patients included in this study were diagnosed using adrenal vein sampling (AVS), which demonstrated lateralization of excess aldosterone production. All patients responded to adrenalectomy with normalization of aldosterone/ renin ratio (ARR) and with decreased blood pressure and/or normalization of hypokalemia (Table 2). All adenoma cases were histopathologically diagnosed as an adrenocortical adenoma.

\section{Differential gene expression in APA}

To evaluate global changes in gene expression associated with APA, RNA samples from eight adenomas were compared against the corresponding AAG tissue using microarray analysis. A gene list was compiled based on a minimum of a 2.5-fold increased level of expression that was found to be statistically significant $(P<0.05)$. Fourteen genes were identified using these criteria, and a heat map representation of these genes is shown in Fig. 1. Five genes in this list were chosen for qPCR validation, which confirmed the microarray data (Fig. 2, and Table 1). The major gene difference, which was observed in every APA-AAG sample pair, was CYP11B2 (Fig. 2). Microarray data indicated a mean of 9.7-fold increased expression in APA $(P<0.001)$, and the more quantitative method, qPCR, indicated a mean difference of 49-fold (Table 1). A comparison of microarray and qPCR was also performed for Purkinje cell protein 4 (PCP4), pre-B lymphocyte 3
(VPREB3), and paired related homeobox 1 (PRRX1). In each case, qPCR generally agreed with microarray analysis (Table 1).

\section{Steroidogenic enzymes}

Eleven genes involved in the production of all classes of adrenal steroids were analyzed by microarray (Fig. 3). In addition to a 9.7-fold increase in CYP11B2 expression, AKR1C3 (17ß-hydroxysteroid dehydrogenase type 5), CYP17A1 (steroid 17 $\alpha$-hydroxylase/17,20 lyase), and Cytochrome b5 (CYB5) showed significantly lower expression in APA compared with AAG $(P<0.05$; Fig. 3$)$. These genes also showed significant differences between APA and AAG when analyzed by qPCR (Fig. 4, and Table 2). Additionally, microarray analysis did not indicate any significant differences for the expression of cholesterol side-chain cleavage (CYP11A1), StAR protein (StAR), 3ß-hydroxysteroid dehydrogenase (HSD3B2), 21-hydroxylase (CYP21A2), 11ß-hydroxylase (CYP11B1), cytochrome P450 oxidoreductase (POR), or steroid sulfotransferase type 2A1 (SULT2A1; Fig. 3).

\section{Discussion}

In this study, we investigated the molecular mechanisms leading to APA by comparing the whole transcriptome of APA with their AAG tissues. Using microarray analysis, 14 transcripts were significantly elevated in APA, and qPCR assay confirmed the microarray results for the genes of interest. Most of the genes have not

Table 2 Clinical features of the APA patients. Relevant data were collected pre and post surgery, including systolic blood pressure (SBP), diastolic blood pressure (DBP), plasma renin activity (PRA), aldosterone/renin ratio (ARR), and not detectable or not determined (ND). Pre indicates the value obtained before surgery, and post indicates the value obtained after the removal of the APA. Each case number corresponds to the number in the presented heat map figures.

\begin{tabular}{|c|c|c|c|c|c|c|c|c|c|c|}
\hline Case no. & 1 & 2 & 3 & 4 & 5 & 6 & 7 & 8 & 9 & 10 \\
\hline Age & 62 & 73 & 58 & 30 & 51 & 53 & 46 & 48 & 72 & 37 \\
\hline Sex & $\mathrm{M}$ & M & $\mathrm{M}$ & M & $\mathrm{F}$ & $\mathrm{M}$ & M & $\mathrm{F}$ & $\mathrm{F}$ & $\mathrm{M}$ \\
\hline \multicolumn{11}{|l|}{ SBP $(\mathrm{mmHg})$} \\
\hline Pre & 154 & 149 & 167 & 164 & 168 & 183 & 157 & 146 & 158 & 120 \\
\hline Post & 127 & 133 & 131 & 145 & 129 & 148 & 139 & 149 & 141 & 152 \\
\hline \multicolumn{11}{|l|}{$\mathrm{DBP}(\mathrm{mmHg})$} \\
\hline Pre & 92 & 89 & 101 & 103 & 97 & 105 & 92 & 95 & 83 & 90 \\
\hline Post & 81 & 79 & 82 & 86 & 85 & 83 & 86 & 88 & 89 & 82 \\
\hline \multicolumn{11}{|l|}{ Serum $\mathrm{K}^{+}(\mathrm{mEq} / \mathrm{l})$} \\
\hline Pre & 4.2 & 4.7 & 2.5 & 3.4 & 3.9 & 2.9 & 3.7 & 2.4 & 2.2 & 3.1 \\
\hline Post & 4.8 & 4.7 & 3.9 & 4.1 & 4.5 & 3.8 & 3.4 & 5 & 3.9 & 3.8 \\
\hline \multicolumn{11}{|c|}{ Plasma aldosterone (ng/dl) } \\
\hline Pre & 20.9 & 15.8 & 35.3 & 15.4 & 15.8 & 42.7 & 28.3 & 30.8 & 32.7 & 26 \\
\hline Post & ND & 8.7 & 6.2 & 8.1 & 7.9 & 10 & 6 & 17.4 & 11.3 & ND \\
\hline \multicolumn{11}{|l|}{ PRA (ng/ml per h) } \\
\hline Pre & 0.3 & 0.3 & 0.2 & 0.3 & 0.1 & 0.4 & 0.6 & 0.1 & 0.5 & $<0.6$ \\
\hline Post & ND & 0.4 & ND & 0.9 & 1.7 & 3.9 & 0.2 & 0.6 & 0.9 & ND \\
\hline \multicolumn{11}{|c|}{ ARR (ng/dl:ng/ml per h) } \\
\hline Pre & 69.67 & 52.67 & 176.50 & 51.33 & 158.00 & 106.75 & 47.17 & 308.00 & 65.40 & $>43$ \\
\hline Post & ND & 21.75 & ND & 9.00 & 4.65 & 2.56 & 30.00 & 29.00 & 12.56 & ND \\
\hline Tumor size (mm) & 9 & 8 & 14 & 12 & 15 & 18 & 19 & 17 & 18 & 19 \\
\hline
\end{tabular}




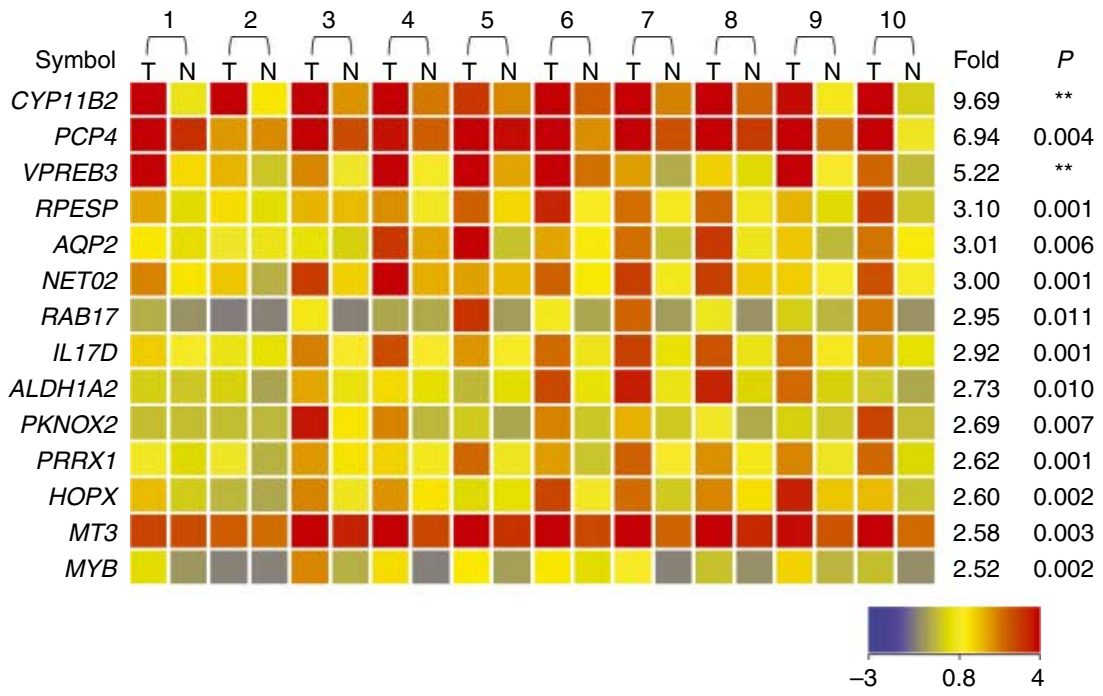

Figure 1 Heat map representation from microarray analysis showing transcripts with elevated expression in APA versus AAG tissue. The list was prepared based on genes that were significantly increased by $>2.5$-fold $(P<0.05)$ in APA compared to AAG. RNA from ten APA-AAG pairs was used for microarray analysis on 20 arrays. The heat map color indicates the expression value of each gene in the corresponding sample based on the $\log _{2}$ of signal strength (see color bar). The mean fold induction of each APA-AAG pair with $P$ value between all APA and AAG using paired $t$-test is also provided $(n=10)$. APA-AAG sample sets are paired by the indicated numbers. ( ${ }^{* *}$ indicates a $P$ value $<0.001, T=$ APA; $N=A A G)$. Full colour version of this figure available via $\mathrm{http}: / / \mathrm{dx}$. doi.org/10.1530/EJE-10-1085. previously been studied in adrenal carcinoma or adenoma tissues, and several are good candidates as regulators of aldosterone secretion $(8,10-12,20-22)$. One such example is PCP4, which is capable of binding calmodulin and regulating the dissociation of calcium from calmodulin $(23,24)$. The calcium-calmodulin cascade plays an important role in the expression of CYP11B2 (11, 13, 25), and therefore PCP4 could participate in regulating aldosterone production. Another example is the gene that encoding PRRX1, a member of the paired family of homeobox proteins which is localized in the nucleus and functions as a transcription co-activator $(26,27)$.

One unique feature of the current study is its use of paired APA-AAG samples from the same patient to study gene expression differences. This comparison led to the identification of several genes not previously noted in APA array studies, in which the control adrenal tissues were from autopsy or patients who underwent adrenalectomy along with a renalectomy due to renal carcinoma. Compared with these adrenal tissues, AAG showed morphological remodeling, but without transcriptional phenotype difference (28). Moreover, APA production of aldosterone causes these patients to have low plasma renin activity and Ang II $(1,5)$. Thus, the adjacent adrenal tissue in this study is exposed to relatively lower Ang II levels, which was not controlled in previous studies $(8,10)$. So the transcriptome comparison with paired APA-AAG could have less variation because these tissues are exposed to the same hormonal milieu. Interestingly, a qPCR analysis showed that CYP11B2 expression between our AAG and normal adrenal gland (obtained from autopsy or renal cancer surgery) was not statistically different; and compared with the normal adrenal glands, the AAG showed smaller variation in CYP11B2 expression (data not shown). This is likely because most subjects, even those without PA, are on a relatively high sodium diet and a relatively inactive glomerulosa. This concept is supported by the use of recently developed CYP11B2 antibodies show that normal adrenal glands exhibit few cells in the glomerulosa with detectable expression (29).

Several studies suggested that APA has altered expression of several genes encoding various steroidogenic enzymes when compared to normal adrenal tissue. This observation has led many to speculate that the abnormal production of aldosterone and 'hybrid' steroids such as 18-oxocortisol by APA tissue may result from the disordered expression of multiple steroidogenic enzymes $(8,11)$. As expected, our microarray data demonstrated that CYP11B2 was expressed at much higher levels in APA compared with AAG. In contrast, most transcripts encoding other steroidogenic enzymes were not different in APA, including StAR, which controls the acute rate-limiting first step in steroidogenesis $(30,31)$. Nevertheless, we

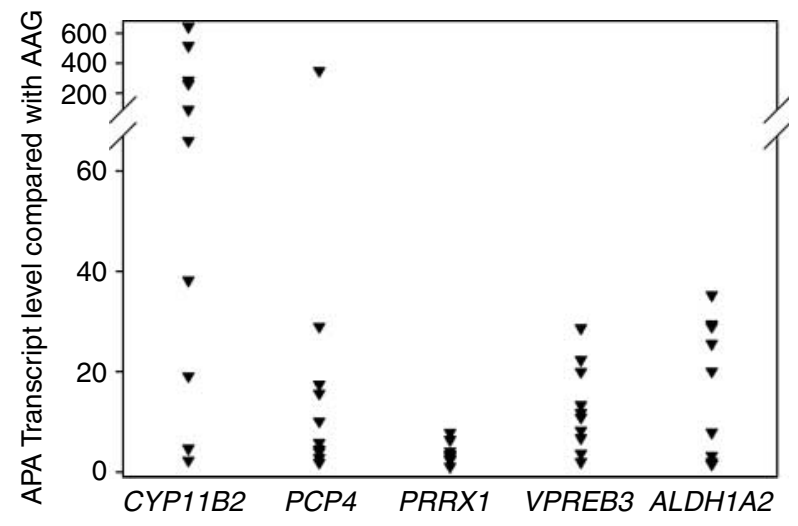

Figure 2 Quantification of up-regulated gene transcripts in APA-AAG pairs using QPCR. The vertical point scatter plot compares the expression of CYP11B2, PCP4, PRRX1, VPREB3, and $A L D H 1 A 2$ between each APA-AAG pairs. Each plot represents the fold change within each sample pair, normalized to 18S rRNA. 


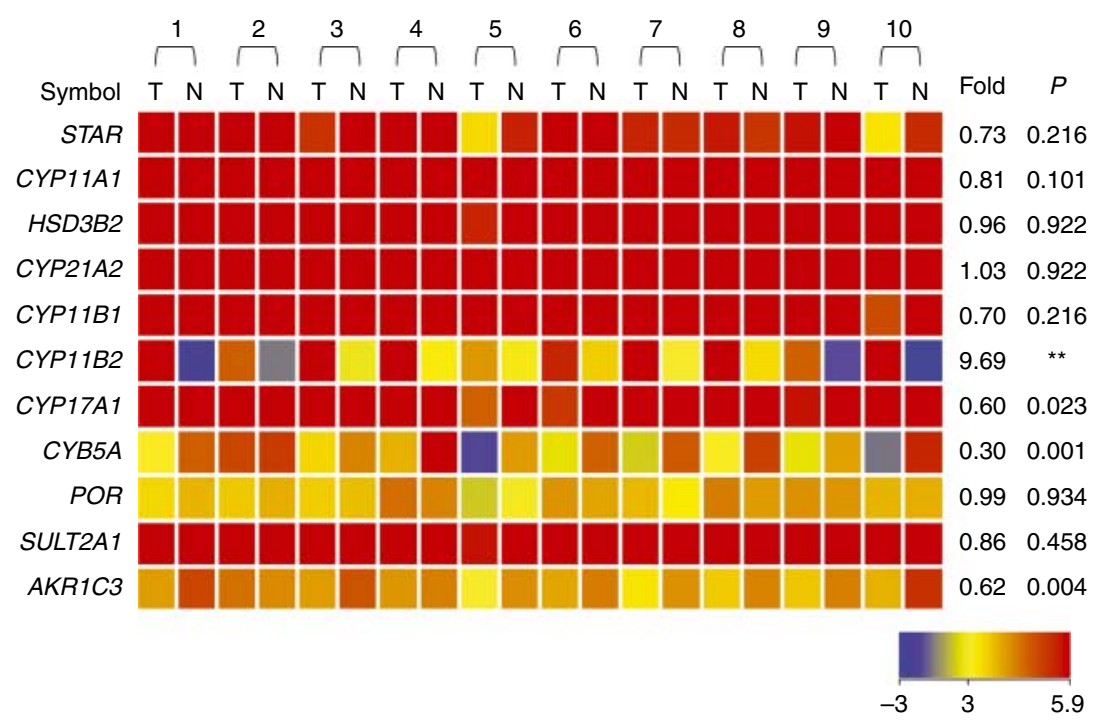

Figure 3 Comparison of steroidogenic enzyme transcripts in APA-AAG pairs using a heat map derived from microarray analysis. RNA from ten APA-AAG pairs was used for microarray analysis on 20 arrays. The heat map color indicates the expression value of each gene in the corresponding sample based on the $\log _{2}$ of signal strength (see color bar). The mean fold induction of each APA-AAG pair is also provided with $P$ value between APA and AAG using paired $t$-test. $(n=10)$. Patient pairs are grouped by the indicated numbers. ${ }^{* *}$ indicates a $P$ value $<0.001, T=$ APA; $N=$ AAG). Full colour version of this figure available via http://dx.doi.org/10.1530/EJE-10-1085. found decreased expression of the transcripts normally associated with adrenal androgen production including AKR1C3, CYP17A1, and CYB5 in APA. These results were consistent with the selectively increased aldosterone production from APA.

In the current study, microarray analysis suggested that the fold difference for CYP11B2 expression was smaller than we and others have previously observed when APA tissue was compared to adrenal glands from autopsy and renal cancer patients $(8,10,32,33)$. However, our qPCR analysis of the CYP11B2 transcript agrees with previous reports of a larger than tenfold difference between APA and normal adrenal tissue (8). This may be related to some cross-reactivity of the Illumina microarray CYP11B2 oligonucleotide with the highly similar $11 \beta$ hydroxylase (CYP11B1) transcripts.

CYP11B2 is overexpressed in APA, which has been widely reported and also confirmed by our study $(1,10,12)$. In vitro and in vivo studies have shown that CYP11B2 expression is mainly regulated by Ang II, whereas PA patients have low plasma renin activity, leaving the mechanism of autonomous CYP11B2 expression in APA unknown. Ye et al. (10) showed that the expression of certain G-protein-coupled receptors (GPCRs) were greatly up-regulated in APA when compared with normal adrenal glands. We found a small but significant increase in the expression of several genes encoding GPCRs in APA using our pairwise comparison, but the overall fold increase was $<2.5$ (data not shown). These results further suggest that some GPCRs may be involved in the molecular mechanisms of APA, at least in some tumors. As noted previously, the ectopic expression of GPCRs may occur in only a small subset of APA (10). Other studies suggest that the expression of transcription factors such as nerve growth factor-induced clone B (NGFIB), steroidogenic factor-1 (SF-1), and dosage-sensitive sex reversal, adrenal hypoplasia congenita critical region on the $\mathrm{X}$ chromosome gene $1(D A X-1)(8)$, or signaling molecules such as calcium/calmodulin-dependent protein kinase I (CAMK I) might increase CYP11B2 expression in APA (12); however, these genes were not found to be differentially up-regulated in our study using pair-wise comparison.

Microarray analysis probes tens of thousands of genes simultaneously; therefore, it has become a useful tool to identify genes involved in tumorigenesis (18, 33-36). Several lines of evidence support the validity of our microarray analysis. First, our microarray results are in general agreement with the data obtained from qPCR. Second, a high CYP11B2 expression and low expression of AKR 1C3, CYP17, and CYB5 are found in APA tissue, which is consistent with previous studies $(8,11,32)$. Our results also indicate a series of novel genes, which are highly expressed along with CYP11B2 in APA. These transcripts sort with CYP11B2 as markers for

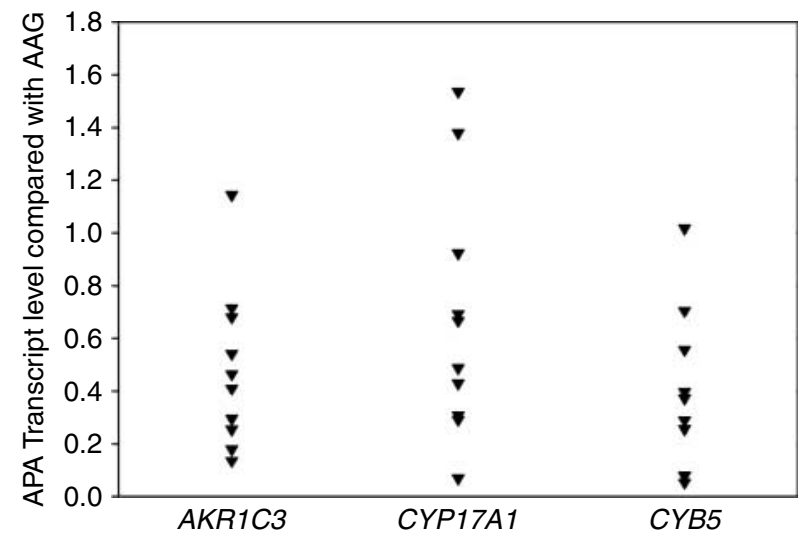

Figure 4 Quantification of the selected steroidogenic enzyme gene transcripts in APA-AAG pairs using qPCR. The vertical point scatter plot compares the expression of CYP17, CYB5, and AKR1C3 between APA and AAG. Each plot represents the fold change within each sample pair normalized to18S rRNA. 
APA versus AAG and could contribute to Ang II-independent CYP11B2 expression, aldosterone production, and growth in APA. Elucidating the action of these genes in the adrenal cortex and APA might identify important mechanisms of APA growth and function, which might then lead to new strategies to diagnose and treat PA.

\section{Declaration of interest}

The authors declare that there is no conflict of interest that could be perceived as prejudicing the impartiality of the research reported.

\section{Funding}

This work was supported by National Institutes of Health Grants DK-43140 (to W E Rainey), a Synergy Award from the Cardiovascular Discovery Institute, Medical College of Georgia (to W E Rainey and M A Edwards), a Clinical Scientist Award in Translational Research from the Burroughs-Wellcome Fund (\#1005954 to R J Auchus), and the Houston J and Florence A Doswell Center for the Development of New Approaches for the Treatment of Hypertension at UT Southwestern.

\section{Acknowledgement}

We would also like to acknowledge the editorial assistance of Dr Mary Bassett.

\section{References}

1 Rossi GP, Bernini G, Caliumi C, Desideri G, Fabris B, Ferri C, Ganzaroli C, Giacchetti G, Letizia C, Maccario M, Mallamaci F, Mannelli M. Mattarello MJ. Moretti A, Palumbo G, Parenti G, Porteri E, Semplicini A, Rizzoni D, Rossi E, Boscaro M, Pessina AC \& Mantero F. A prospective study of the prevalence of primary aldosteronism in 1,125 hypertensive patients. Journal of the American College of Cardiology 200648 2293-2300. (doi:10. 1016/j.jacc.2006.07.059)

2 Gordon RD. Primary aldosteronism - actual epidemics or false alarm? Arquivos Brasileiros de Endocrinologia e Metabologia $2004 \mathbf{4 8}$ 666-673. (doi:10.1590/S0004-27302004000500012)

3 Heymes C, Garnier A, Fuchs S, Bendall JK, Nehme J, Ambroisine ML, Robidel E, Swynghedauw B, Milliez P \& Delcayre C. Aldosterone-synthase overexpression in heart: a tool to explore aldosterone's effects. Molecular and Cellular Endocrinology 2004217 213-219. (doi:10.1016/j.mce.2003.10.022)

4 Rossi GP, Bernini G, Desideri G, Fabris B, Ferri C, Giacchetti G, Letizia C, Maccario M, Mannelli M, Matterello MJ, Montemurro D, Palumbo G, Rizzoni D, Rossi E, Pessina AC \& Mantero F. Renal damage in primary aldosteronism: results of the PAPY study. Hypertension 200648 232-238. (doi:10.1161/01.HYP.0000230 444.01215.6a)

5 Stowasser M. Update in primary aldosteronism. Journal of Clinical Endocrinology and Metabolism 200994 3623-3630. (doi:10. 1210/jc.2009-1399)

6 Plouin PF, Amar L \& Chatellier G. Trends in the prevalence of primary aldosteronism, aldosterone-producing adenomas, and surgically correctable aldosterone-dependent hypertension. Nephrology, Dialysis, Transplantation 200419 774-777. (doi:10. 1093/ndt/gfh112)

7 Mattsson C \& Young WF Jr. Primary aldosteronism: diagnostic and treatment strategies. Nature Clinical Practice. Nephrology 20062 198-208 (quiz, $191 \mathrm{p}$ following 230). (doi:10.1038/ncpneph 0151)
8 Bassett MH, Mayhew B, Rehman K, White PC, Mantero F, Arnaldi G, Stewart PM, Bujalska I \& Rainey WE. Expression profiles for steroidogenic enzymes in adrenocortical disease. Journal of Clinical Endocrinology and Metabolism 200590 5446-5455. (doi:10.1210/jc.2005-0836)

9 Connell JM, Fraser R, MacKenzie SM, Friel EC, Ingram MC, Holloway CD \& Davies E. The impact of polymorphisms in the gene encoding aldosterone synthase (CYP11B2) on steroid synthesis and blood pressure regulation. Molecular and Cellular Endocrinology 2004217 243-247. (doi:10.1016/j.mce.2003.10.025)

10 Ye P, Mariniello B, Mantero F, Shibata H \& Rainey WE. G-proteincoupled receptors in aldosterone-producing adenomas: a potential cause of hyperaldosteronism. Journal of Endocrinology 2007195 39-48. (doi:10.1677/JOE-07-0037)

11 Lenzini L, Seccia TM, Aldighieri E, Belloni AS, Bernante P, Giuliani L, Nussdorfer GG, Pessina AC \& Rossi GP. Heterogeneity of aldosterone-producing adenomas revealed by a whole transcriptome analysis. Hypertension 200750 1106-1113. (doi:10.1161/ HYPERTENSIONAHA.107.100438)

12 Saner-Amigh K, Mayhew BA, Mantero F, Schiavi F, White PC, Rao CV \& Rainey WE. Elevated expression of luteinizing hormone receptor in aldosterone-producing adenomas. Journal of Clinical Endocrinology and Metabolism 200691 1136-1142. (doi:10. 1210/jc.2005-1298)

13 Bassett MH, White PC \& Rainey WE. The regulation of aldosterone synthase expression. Molecular and Cellular Endocrinology 2004 217 67-74. (doi:10.1016/j.mce.2003.10.011)

14 Holland OB, Carr B \& Brasier AR. Aldosterone synthase gene regulation by angiotensin. Endocrine Research 199521 455-462. (doi:10.3109/07435809509030462)

15 Szekeres M, Turu G, Orient A, Szalai B, Supeki K, Cserzo M, Varnai P \& Hunyady L. Mechanisms of angiotensin II-mediated regulation of aldosterone synthase expression in H295R human adrenocortical and rat adrenal glomerulosa cells. Molecular and Cellular Endocrinology 2009302 244-253. (doi:10.1016/j.mce. 2008.12.015)

16 Kempers MJ, Lenders JW, van Outheusden L, van der Wilt GJ, Schultze Kool LJ, Hermus AR \& Deinum J. Systematic review: diagnostic procedures to differentiate unilateral from bilateral adrenal abnormality in primary aldosteronism. Annals of Internal Medicine 2009151 329-337.

17 Giacchetti G, Mulatero P, Mantero F, Veglio F, Boscaro M \& Fallo F. Primary aldosteronism, a major form of low renin hypertension: from screening to diagnosis. Trends in Endocrinology and Metabolism 200819 104-108. (doi:10.1016/j.tem.2008.01.005)

18 Slater EP, Diehl SM, Langer P, Samans B, Ramaswamy A, Zielke A \& Bartsch DK. Analysis by cDNA microarrays of gene expression patterns of human adrenocortical tumors. European Journal of Endocrinology 2006154 587-598. (doi:10.1530/eje.1.02116)

19 Pezzi V, Mathis JM, Rainey WE \& Carr BR. Profiling transcript levels for steroidogenic enzymes in fetal tissues. Journal of Steroid Biochemistry and Molecular Biology 200387 181-189. (doi:10. 1016/j.jsbmb.2003.07.006)

20 Soon PS, Gill AJ, Benn DE, Clarkson A, Robinson BG, McDonald KL \& Sidhu SB. Microarray gene expression and immunohistochemistry analyses of adrenocortical tumors identify IGF2 and Ki-67 as useful in differentiating carcinomas from adenomas. EndocrineRelated Cancer 200916 573-583. (doi:10.1677/ERC-08-0237)

21 Suh I, Guerrero MA \& Kebebew E. Gene-expression profiling of adrenocortical carcinoma. Expert Review of Molecular Diagnostics 20099 343-351. (doi:10.1586/erm.09.13)

22 Tacon LJ, Soon PS, Gill AJ, Chou AS, Clarkson A, Botling J, Stalberg PL, Skogseid BM, Robinson BG, Sidhu SB \& CliftonBligh RJ. The glucocorticoid receptor is overexpressed in malignant adrenocortical tumors. Journal of Clinical Endocrinology and Metabolism 200994 4591-4599. (doi:10.1210/jc.20090546)

23 Johanson RA, Sarau HM, Foley JJ \& Slemmon JR. Calmodulinbinding peptide PEP-19 modulates activation of calmodulin kinase II in situ. Journal of Neuroscience 200020 2860-2866. 
24 Kleerekoper QK \& Putkey JA. PEP-19, an intrinsically disordered regulator of calmodulin signaling. Journal of Biological Chemistry 2009284 7455-7464. (doi:10.1074/jbc.M808067200)

25 Spat A \& Hunyady L. Control of aldosterone secretion: a model for convergence in cellular signaling pathways. Physiological Reviews 2004 84 489-539. (doi:10.1152/physrev.00030.2003)

26 Hernandez Perera O, Marrero A \& Rodriguez Perez JC. What are the Hox genes? Its importance in vascular and renal disease. Nefrologia 200626 195-205.

27 Noda M, Ohno S \& Nakajin S. Mono-(2-ethylhexyl) phthalate (MEHP) induces nuclear receptor 4A subfamily in NCI-H295R cells: a possible mechanism of aromatase suppression by MEHP. Molecular and Cellular Endocrinology 2007 274 8-18. (doi:10. 1016/j.mce.2007.05.004)

28 Boulkroun S, Samson-Couterie B, Dzib JF, Lefebvre H, Louiset E, Amar L, Plouin PF, Lalli E, Jeunemaitre X, Benecke A, Meatchi T \& Zennaro MC. Adrenal cortex remodeling and functional zona glomerulosa hyperplasia in primary aldosteronism. Hypertension 201056 885-892. (doi:10.1161/HYPERTENSIONAHA.110. 158543)

29 Nishimoto K, Nakagawa K, Li D, Kosaka T, Oya M, Mikami S, Shibata H, Itoh H, Mitani F, Yamazaki T, Ogishima T, Suematsu M \& Mukai K. Adrenocortical zonation in humans under normal and pathological conditions. Journal of Clinical Endocrinology and Metabolism 2010 95 2296-2305. (doi:10.1210/jc.2009-2010)

30 Arakane F, Sugawara T, Nishino H, Liu Z, Holt JA, Pain D, Stocco DM, Miller WL \& Strauss JF III. Steroidogenic acute regulatory protein (StAR) retains activity in the absence of its mitochondrial import sequence: implications for the mechanism of StAR action. PNAS 199693 13731-13736. (doi:10.1073/ pnas.93.24.13731)
31 Rone MB, Fan J \& Papadopoulos V. Cholesterol transport in steroid biosynthesis: role of protein-protein interactions and implications in disease states. Biochimica et Biophysica Acta 20091791 646-658. (doi:10.1016/j.bbalip.2009.03.001)

32 Assie G, Auzan C, Gasc JM, Baviera E, Balaton A, Elalouf JM, Jeunemaitre X, Plouin PF, Corvol P \& Clauser E. Steroidogenesis in aldosterone-producing adenoma revisited by transcriptome analysis. Journal of Clinical Endocrinology and Metabolism 2005 90 6638-6649. (doi:10.1210/jc.2005-1309)

33 Lombardi CP, Raffaelli M, Pani G, Maffione A, Princi P, Traini E, Galeotti T, Rossi ED, Fadda G \& Bellantone R. Gene expression profiling of adrenal cortical tumors by cDNA macroarray analysis. Results of a preliminary study. Biomedicine and Pharmacotherapy 200660 186-190. (doi:10.1016/j.biopha.2006.03.006)

34 Quackenbush J. Microarray analysis and tumor classification. New England Journal of Medicine 2006354 2463-2472. (doi:10.1056/ NEJMra042342)

35 Giordano TJ, Kuick R, Else T, Gauger PG, Vinco M, Bauersfeld J, Sanders D, Thomas DG, Doherty G \& Hammer G. Molecular classification and prognostication of adrenocortical tumors by transcriptome profiling. Clinical Cancer Research $2009 \quad 15$ 668-676. (doi:10.1158/1078-0432.CCR-08-1067)

36 Laurell C, Velazquez-Fernandez D, Lindsten K, Juhlin C, Enberg U, Geli J, Hoog A, Kjellman M, Lundeberg J, Hamberger B, Larsson C, Nilsson P \& Backdahl M. Transcriptional profiling enables molecular classification of adrenocortical tumours. European Journal of Endocrinology 2009161 141-152. (doi:10.1530/EJE-09-0068)

Received 18 November 2010

Accepted 19 January 2011 